\title{
Nuclear radioactive techniques applied to materials research
}

\author{
J.G. Correia ${ }^{1}$, K. Johnston ${ }^{2,3}$ and U. Wahl ${ }^{1}$ \\ ${ }^{1}$ Instituto Tecnológico e Nuclear, E.N. 10, 2686-953 Sacavém, Portugal \\ ${ }^{2}$ Technische Physik, Universität des Saarlandes, D-66041 Saarbrücken, Germany \\ ${ }^{3}$ CERN, PH Div, CH-1211 Geneva 23, Switzerland
}

\begin{abstract}
In this paper we review materials characterization techniques using radioactive isotopes at the ISOLDE/CERN facility. At ISOLDE intense beams of chemically clean radioactive isotopes are provided by selective ion-sources and high-resolution isotope separators, which are coupled on-line with particle accelerators. There, new experiments are performed by an increasing number of materials researchers, which use nuclear spectroscopic techniques such as Mössbauer, Perturbed Angular Correlations (PAC), $\beta$-NMR and Emission Channeling with short-lived isotopes not available elsewhere. Additionally, diffusion studies and traditionally non-radioactive techniques as Deep Level Transient Spectroscopy, Hall effect and Photoluminescence measurements are performed on radioactive doped samples, providing in this way the element signature upon correlation of the time dependence of the signal with the isotope transmutation half-life. Current developments, applications and perspectives of using radioactive ion beams and techniques in solid state and biophysics research are presented with a few examples.
\end{abstract}

Keywords: Materials characterization / Nanoscopic scale phenomena / Radioactive spectroscopic techniques / Radioactive tracer techniques / Radioactive ion beams,

Author for correspondence email: guilherme.correia@itn.pt 


\section{The ISOLDE facility at CERN}

\subsection{The production of radioactive isotopes}

Radioactivity and Radioactive Isotopes (RI) are ordinarily present in daily life, contributing directly or indirectly to welfare as well as, more specifically, to both the applied science and research fields. Presently, three types of facilities produce the required excited and unstable nuclei, covering the full mass range, i.e., neutron-rich isotopes (reactors), proton-rich isotopes (cyclotrons) or both, when using high-energy proton induced reactions. Among the different and specific methods for delivery of RI, the production of radioactive ion beams (RIB) provides the most versatile and fastest delivery of the nuclei species, justifying the large investment in new RIB facilities, which are dedicated to a wide range of research and applications all-over the world [1].

Since its start in 1967, the ISOLDE facility at CERN has been successfully pioneering the thick target technologies for RIB production. There, an efficient and continuing R\&D program has been constantly improving beam quality with high intensities and high elemental purity, diversifying element species and increasing the energy of delivered beams. This dynamic enables, on one hand, a steadily growing community of (young) users covering a wide range of research, which feeds back, and on the other, with resourced motivation for a continued development and coexistence of nuclear, atomic, solid state and biophysics research.

At ISOLDE the radioactive nuclei are produced through spallation, fission or fragmentation reactions in thick targets by the $1.4 \mathrm{GeV}(1-2 \mu \mathrm{A})$ proton beam from the CERN PS-Booster [2 - 5]. The target material and morphology are chosen to optimize production and release time of the desired isotope. The mass range mainly determines the target species $\left(\mathrm{UC}_{2}, \mathrm{ThO}, \mathrm{CaO}, \mathrm{ZrO}, \mathrm{YO}, \mathrm{SiC}, \mathrm{Ta}, \mathrm{Nb}, \mathrm{Sn}, \mathrm{Pb}\right.$ ) while the half-lives determine the morphology (solid discs, foils, powders, or liquid and nanostructured materials) aiming to optimize production and extraction of the desired isotopes. The target container is made of tantalum and heated to very high temperatures to allow the reaction products to diffuse within the target material and reach the surface. Then, by releasing from the target surface the radioactive elements are vaporized and conducted by a transfer line into several types of element-selective ion sources. In this way, the ISOLDE group develops different types of element-specific target-ion-source combinations that allow the use of more than 1000 radioactive isotopes and isobars of about 75 elements.

For two decades, efforts have been successful in improving the element selectivity at ISOLDE by developing state-of-the-art ion-sources consisting of tuneable multi-wave laser beams, which provide 
clean radioactive beams of, e.g., $\mathrm{Ag}, \mathrm{Ni}, \mathrm{Mn}, \mathrm{Be}, \mathrm{Cu}, \mathrm{Zn}$ and $\mathrm{Cd}[6$ - 9]. The extracted ions are then accelerated to $60 \mathrm{keV}$ and mass $(\mathrm{M})$ separated by analyzing magnets.

Two independent mass separators are available at ISOLDE: - the General Purpose Separator (GPS) provides mass separation with a resolving power $M / \Delta M=2400$ for $20 \mathrm{~mm} \mathrm{mrad}$ beams. It is designed to provide up to three simultaneous beams, within a mass range of $\pm 15 \%$, delivered to the beam lines in the experimental hall. The second mass separator, the High Resolution Separator (HRS), is equipped with two bending magnets achieving routinely $\mathrm{M} / \Delta \mathrm{M}>6,000$.

To post-accelerate radioactive ion beams a low cost radio frequency quadrupole (RFQ) acceleration Linac [10 - 13] has been coupled to the low energy ISOLDE beam line. Before the Linac, the primary ISOLDE beam is continuously injected into a Penning trap which transforms a continuous (1+) beam to a bunch of cooled ions. These are then transferred to an Electron Beam Ion Source (EBIS) in order to achieve a charge to mass ratio larger than 1/4.5. After selection of the desired charge to mass ratio by dipole magnets, the ions are gradually accelerated by a RFQ-structure, an interdigital H-type (IH) structure and three 7-gap resonators to a final energy of about $2.2 \mathrm{MeV} / \mathrm{u}$. An efficiency of about $10 \%$ is achieved, essentially given by the EBIS ionization efficiency. For investigations in solid-state physics, lower energies between 1 and $10 \mathrm{MeV} / \mathrm{A}$ can be obtained. For energies below $1 \mathrm{MeV} / \mathrm{A}$, a low charged ion beam (4+) coming out of the EBIS could be injected through an electrostatic high voltage $0-260 \mathrm{kV}$ acceleration lens [14].

The post-acceleration of the ISOLDE beams opens new perspectives, particularly to produce polarized beams with the tilted foil technique. Presently, the feasibility of using polarized beams and $\beta$-NMR to study the binding of metal ions $(\mathrm{Cu}, \mathrm{Fe}, \mathrm{Co}, \mathrm{Zn}, \mathrm{Mo}, \mathrm{Ni})$ to biological macromolecules is being tested [15]. Since ever more energetic radioactive beams have a wide range of applications in nuclear and astrophysics research, CERN has recently approved the HIE-ISOLDE upgrade project [16], to be commissioned by 2016. This RIB upgrade contains three major issues: higher energies, improvements in beam quality and flexibility, and higher beam intensities, which require developments in radioisotope selection, improvements in charge breeding and target-ion source development. Most of the existing REX accelerating structure will be replaced by a superconducting linear accelerator with a maximum energy of $10 \mathrm{MeV} / \mathrm{u}$. In this way all ISOLDE beams will be available within a large spectrum of energies, well below and significantly above the Coulomb barrier, boosting a large programme of nuclear structure and nuclear astrophysics studies using different classes of nuclear reactions. 


\subsection{Radioisotopes for materials and life sciences}

The high intensity and wide range of radioactive isotopes has made ISOLDE a unique facility for solid-state and life science research. Such a scientific program was started in the late seventies with some pioneering experiments, e.g., by implanting the short-lived ${ }^{111 \mathrm{~m}} \mathrm{Cd}$ and ${ }^{119} \mathrm{Cd}$ isotopes into noncubic metals to study electric field gradients of impurities in metals [17]. Since then the work at ISOLDE has diversified, as previously reported in several reviews [18 - 28].

Figure 1 illustrates the panoply of elements which are produced at ISOLDE and have at least one radioactive isotope suitable for use as nanoscopic probes in solid-state and biophysics research. The whole spectrum of sophisticated techniques, which are being used at ISOLDE can essentially be divided into two groups:

1) TRACER TECHNIQUES where the half-life or simply the decay particles provide the element signature information and quantification.

2) NUCLEAR TECHNIQUES where the impurity/element position on lattice sites is directly measured, or where the probe element interaction with the host matrix is investigated via the measurement of the electronic charge density and symmetry, or of the magnetic fields, in the probe's neighbourhood. 


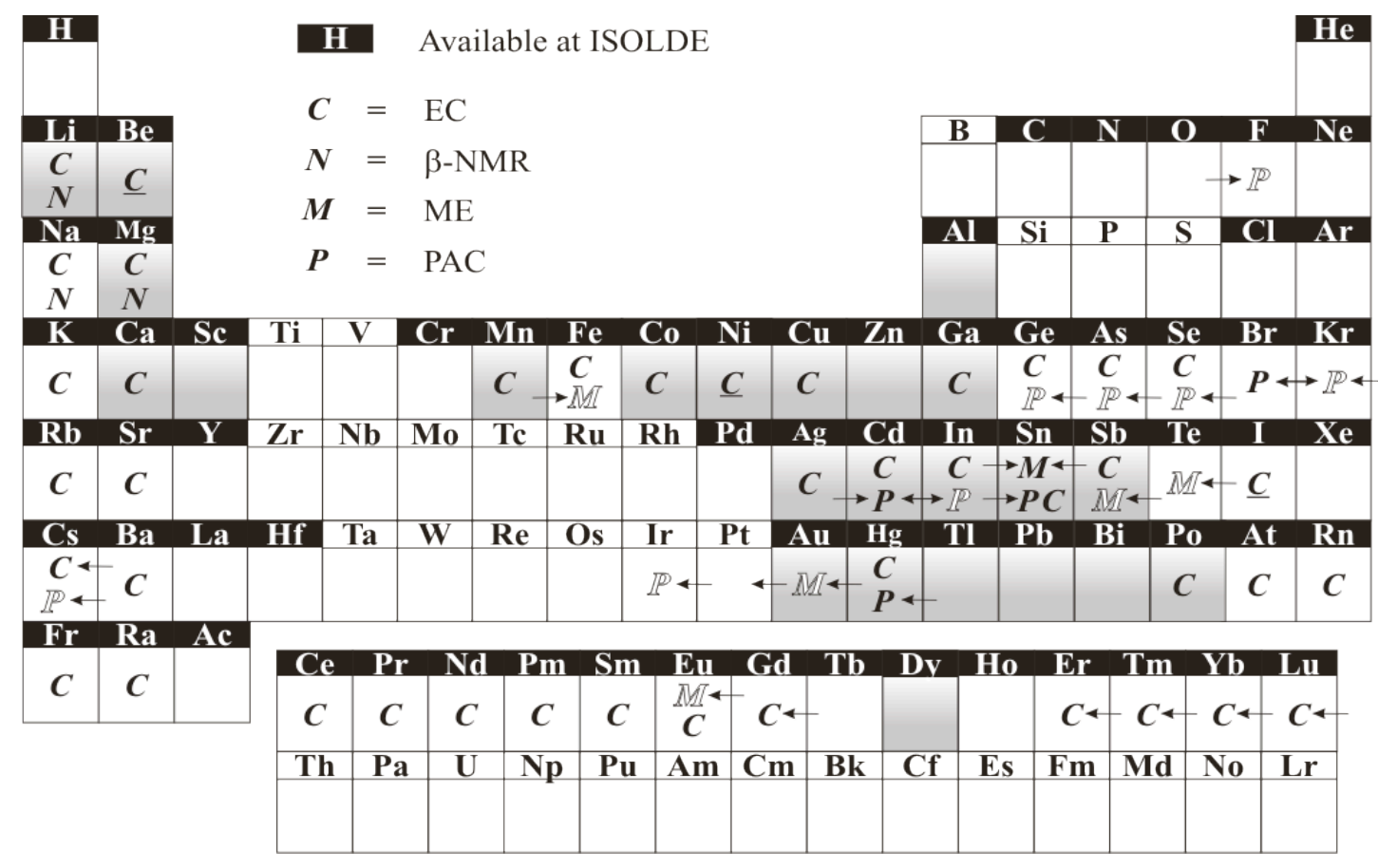

Figure 1: Periodic table of the elements produced as primary beams at ISOLDE. Shadowed frames show elements for which currently highly pure beams are produced with the laser ion-source. Elements that have isotopes, which are adequate for applied research at ISOLDE are also shown. Open N, M, P symbols assign probe elements with suitable cascades for $\beta$-NMR, Mössbauer or Perturbed Angular Correlations, respectively, when these are only obtained by $\beta^{-}$- decay (as indicated by the left arrow $\rightarrow$ ) or when obtained by electron capture and $\beta^{+}-$decay ( $\leftarrow$ ). Closed symbols assign the existence of isotopes allowing the measurements to be done at the parent element without transmutation. Emission channeling, EC, studies and "tracer" techniques that only require charged particle emission and suitable decay half-lives are among the most versatile techniques, with almost all of the periodic table available for experiments. Underlined symbols indicate foreseen candidates for experiments. 


\section{2 - Tracer Techniques}

\subsection{Diffusion studies}

Diffusion of impurity atoms in crystals can be studied by techniques like secondary ion mass spectroscopy (SIMS) or spreading resistance profiling (SRP), which have been developed to study diffusion profiles with depth resolutions of the order of nanometres. For specific applications such as highly diluted systems, self-diffusion and, in particular, studies of amorphous materials, radioactive tracers are particularly useful. The sensitivity is increased by orders of magnitude and, when combined with ion implantation, it avoids the deposition of thin transition-metal layer on the amorphous material which leads to significant modifications of the recrystallization temperatures. Back in the twenties, the first solid state physics experiment using radioisotopes was reported by G. v. Hevesy with the study of self-diffusion in solid lead (1921) by using the natural radioactive isotopes ${ }^{210} \mathrm{~Pb}$ and ${ }^{212} \mathrm{~Pb}$ [29]. An older example of such a kind of studies at ISOLDE is the finding of anomalous diffusion of low concentrations of gold in amorphous silicon, where it is shown that interstitial diffusion of $\mathrm{Au}$ in a-Si is significantly retarded by the presence of intrinsic defects, presumably immobile vacancy-type defects which trap the Au atoms [30].

An environment - such as at ISOLDE - where nuclear and solid-state physicists work side-byside, provides a fertile ground for developing sensitive new methods. In a different type of experiment, $\alpha$-particles emitted from the decay of implanted short-lived nuclei furnished a promising tool for diffusion profiling, due to the fact that the energy spectrum of the $\alpha$-particles is particularly sensitive to the path length travelled within the sample. A test experiment using this method showed that the diffusion coefficient of ${ }^{221} \mathrm{Fr}$ implanted in potassium is several orders of magnitude larger than the potassium self diffusion coefficient [31].

In recent years tracer diffusion studies have dealt with transition metal diffusion in CdTe [32 37], diffusion of $\mathrm{Be}, \mathrm{Ga}$, and $\mathrm{Sn}$ in Ge and SiGe alloys [38], of Be in glassy carbon [39, 40] and of Mn in GaAs [41]. Of particular technological importance is the fact that the diffusion of charged dopant atoms is strongly affected by the presence of an internal electric field [42]. As a consequence, if an inhomogeneous distribution of charged defects is present, an internal electric field is generated acting on any charged particle present in the semiconductor. An internal electric field can also be generated exclusively by intrinsic defects if they act as donors and acceptors and are inhomogeneously distributed. One example of these phenomena is the diffusion of $\mathrm{Ag}$, and, to a lesser extent also, of $\mathrm{Cu}$ in CdTe, which shows several very unusual properties depending on the sample conditions before diffusion and on the external conditions during diffusion. 
Figure 2 shows a selected example of such type of diffusion behaviours where several concentration profiles are presented for the radiotracers ${ }^{111} \mathrm{Ag},{ }^{67} \mathrm{Cu},{ }^{193} \mathrm{Au}$, and ${ }^{24} \mathrm{Na}$ measured in $\mathrm{CdTe}$ crystals after implantation and subsequent diffusion under external Cd vapour pressure.

All profiles are symmetrical with respect to the centre of the samples and exhibit 100-250 $\mu \mathrm{m}$ layers, below both surfaces, with low diffuser concentrations. Since the diffusion starts from a sharp, implanted profile on one surface as compared to the thickness of the crystal, the dopant atoms have to diffuse throughout the samples, from low to high concentration, in order to form this type of profile. Such unusual diffusion behaviour is called uphill diffusion and is due to the fact that these particular tracer elements are all fast interstitial diffusers, which are also electrically active interstitial donors, e.g. $\mathrm{Ag}_{\mathrm{i}}{ }^{+}, \mathrm{Na}_{\mathrm{i}}{ }^{+}$. The CdTe crystals are initially Te-rich but upon diffusion under a $\mathrm{Cd}$ atmosphere the surface regions become Cd-rich due to the in-diffusion of interstitial $\mathrm{Cd}_{\mathrm{i}}$. Since intrinsic CdTe point defects such as $\mathrm{Cd}_{\mathrm{i}}$ and $\mathrm{Cd}$ vacancies, $\mathrm{V}_{\mathrm{Cd}}$, form shallow donor and acceptor levels in the band gap, upon diffusion under $\mathrm{Cd}$ atmosphere $p n$-junctions are established on both sides of the crystal. This is a consequence of the fact that $n$-type regions with Cd-excess develop near both surfaces while a $p$-type region with Te-excess remains in the center of the samples. When in thermal equilibrium with the host crystal, the fast interstitial donor impurities will mirror the profile of the electric potential across the crystal, in the present cases, by increasing the concentration in the Te rich region.

The extended research program envisaged on these subjects at ISOLDE can be found in ref. [43]. For this purpose a new setup is being commissioned at the University of Saarbrücken, which will allow implantation, annealing, sectioning of the sample by ion sputtering, and measurement of short-lived tracers (few minute half-lives) by detecting the decay-radiation, in situ. 


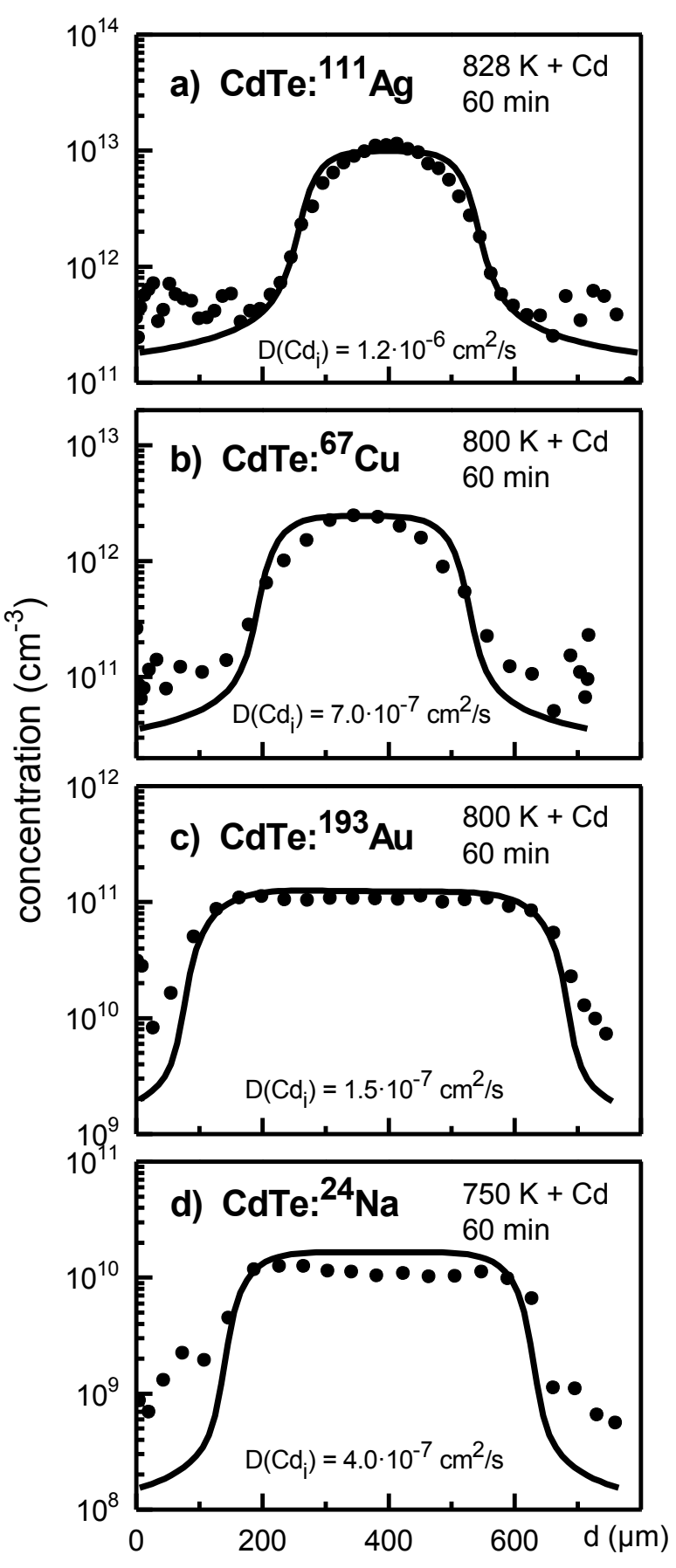

Figure 2: Uphill diffusion profiles measured for the radiotracers ${ }^{111} \mathrm{Ag},{ }^{67} \mathrm{Cu},{ }^{193} \mathrm{Au}$, and ${ }^{24} \mathrm{Na}$ in $\mathrm{CdTe}$ annealed under $\mathrm{Cd}$ atmosphere. The solid lines are simulations according to the model described in Ref. [33]. Note that the left and right end of the d-axis correspond to the two surfaces of the $\sim 750 \mu \mathrm{m}$ thick samples. 


\subsection{Non-standard tracer studies}

About 25 years were needed from the first, unsuccessful attempts [44], to develop new "tracer" techniques combining standard electrical or optical measurements - commonly used in semiconductor physics, with the use of radioactive isotopes. It was first successfully demonstrated with the identification of the Deep Level Transient Spectroscopy (DLTS) signals from Au and Pt implanted Si, that when the radioactive decay involves the chemical transmutation of the dopant, the electrical properties of the semiconductors will change in time with the characteristic time constant of the radioactive decay [45]. Immediately after, techniques as Hall effect [46], DLTS, Capacitance-Voltage measurements [47, 48] and Photoluminescence Spectroscopy [49, 50] have proven to be quite useful when using radioactive isotopes to overcome the chemical "blindness" of non-radioactive methods, in studies of the electrical activation of impurities in intrinsic, III-V [51], and II-VI compound semiconductors [52].

Figure 3 shows one of the first - but illustrative - examples of PL spectra performed on samples doped with radioactive isotopes. In that work ${ }^{111}$ In (2.83d) was implanted into MBE-grown GaAs and the PL spectra were measured as a function of time. The spectra show the increase with time of two PL peaks (at higher wavelengths, to the right of a peak identified as being due to the sample's carbon contamination) which could be clearly assigned to ${ }^{111} \mathrm{Cd}_{\mathrm{Ga}}$ acceptors generated from the decay of ${ }^{111} \mathrm{In}$ at Ga sites [51]. 


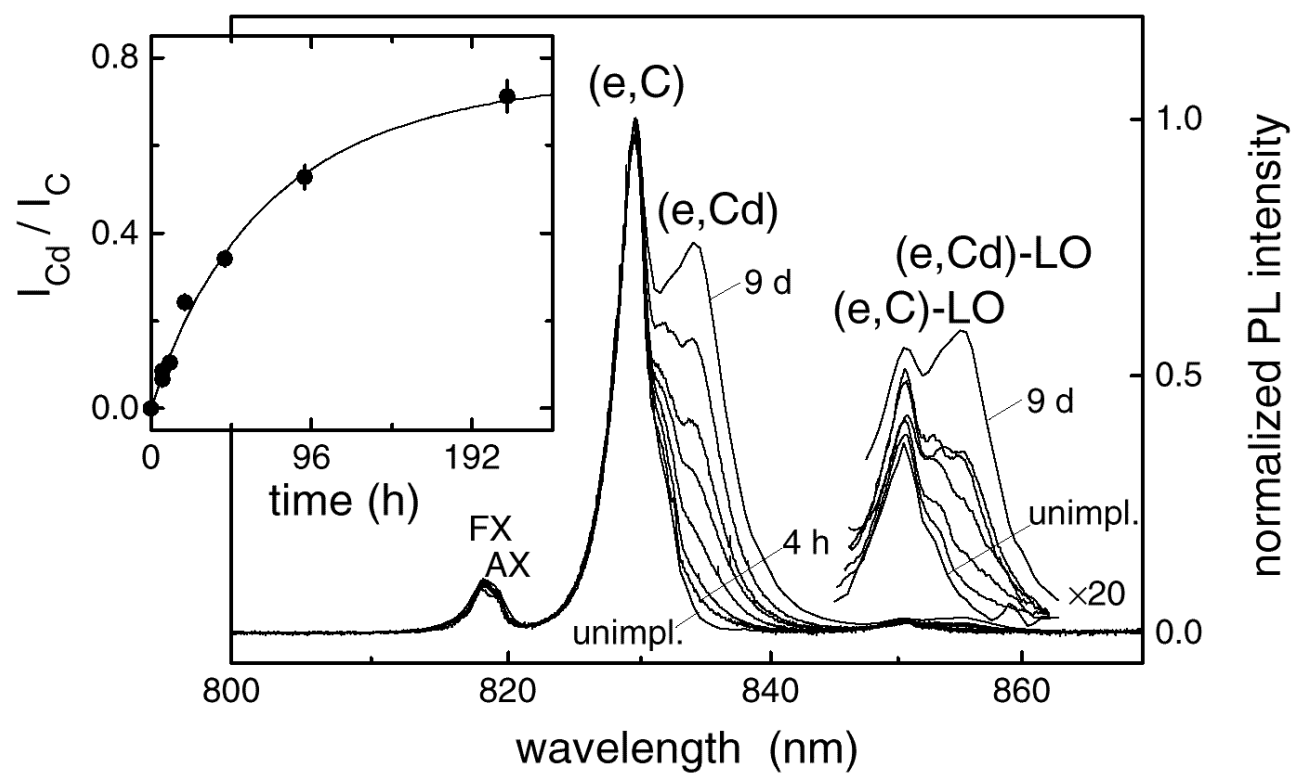

Figure 3: Examples of PL spectra of undoped and ${ }^{111}$ In doped GaAs successively taken 4 h, 7 h, 12 h, 22 h, 2 d, 4 $\mathrm{d}$, and $9 \mathrm{~d}$ after doping. All spectra are normalized to the intensity of the $(e, C)$ peak. In the inset, the height $\mathrm{I}_{\mathrm{Cd}} / \mathrm{I}_{\mathrm{C}}$ of the $(\mathrm{e}, \mathrm{Cd})$ peak in these spectra is shown as a function of time after doping with ${ }^{111} \mathrm{In}$. The solid line is a fit to the data, which includes the characteristic decay time constant of the ${ }^{111} \mathrm{In} \rightarrow{ }^{111} \mathrm{Cd}$ nuclear transmutation, as explained in Ref. [51]. Reprinted with permission from Ref. [51]. Copyright 1995, American Physical Society.

More recently, the properties of donor-related impurities in $\mathrm{ZnO}$ were studied using both stable atom implantations and radiotracer techniques [53]. Photoluminescence measurements were performed as a function of time, on $\mathrm{ZnO}$ implanted with radioactive isotopes ${ }^{72} \mathrm{Zn}$ and ${ }^{73} \mathrm{Ga}$. The first of these isotopes decays to stable ${ }^{72} \mathrm{Ge}$ via ${ }^{72} \mathrm{Ga}$, with half-lives of $46 \mathrm{~h}$ and $14 \mathrm{~h}$, while the latter is a direct decay to stable ${ }^{73} \mathrm{Ge}$ with a half- life of $4.9 \mathrm{~h}$. New data are presented that establish the association between the $\mathrm{I}_{8}$ and $\mathrm{I}_{1}$ bound exciton recombination with $\mathrm{Ga}$, and luminescence attributed to Ge-related deep defects in ZnO. In detail, these experiments clearly identified a donor-related exciton feature $\mathrm{I}^{8}$ at $3.3600 \mathrm{eV}$ originating from bound exciton recombination at $\mathrm{Ga}$ donors. The $\mathrm{I}_{1}$ line at $3.3718 \mathrm{eV}$ is also likely to be due to $\mathrm{Ga}$, and is attributed to ionized Ga donor bound exciton recombination. A feature at 3.3225 $\mathrm{eV}$ is observed following transmutation of radioactive $\mathrm{Ga}$ into stable $\mathrm{Ge}$, and is attributed to $\mathrm{Ge}$.

On a different but quite exciting new topic, it has been found that the use of highly enriched stable ${ }^{28} \mathrm{Si}$ samples could reveal many new features of well-resolved isotopic fingerprints, due to the reduction in the photoluminescence line-width of many deep luminescence centres [54]. This allows for a better characterization of a defect center, as not only the involvement of a specific element but also the number of atoms of that element within the complex can be determined. Using such type of 
isotopically enriched material a consistent working program has been started with the aim to show that many well-known luminescence centers have a different composition than originally supposed. A large number of four- and five-atom luminescence centers involving the elements $\mathrm{Cu}, \mathrm{Au}$, and $\mathrm{Li}$ were already identified and a series of four- and five-atom deep luminescence centers involving a single Pt atom together with $\mathrm{Cu}$ and $\mathrm{Li}$, similar to what has been seen previously for Au-containing luminescence centers has recently been measured [55]. Since there exists only one stable gold isotope in nature $\left({ }^{197} \mathrm{Au}\right)$, ISOLDE was used in order to provide a gold isotope of a different mass, with the same samples being useful for Pt studies after the decay. 


\section{3 - Nuclear Techniques}

Emission Channeling (EC), Mössbauer Effect (ME), Perturbed Angular Correlations (PAC) and $\beta$ Nuclear Magnetic Resonance ( $\beta$-NMR) represent the most common nuclear techniques using radioactive isotopes at ISOLDE. With these techniques, the radioactive nuclei are used as atomic scale spies in matter. They investigate impurity and dopant lattice sites in a single crystal, its local electronic environment in bulk solids, at surfaces and interfaces, and are used also to investigate the behaviour of single atoms attached to matter in molecular form.

All of these techniques depend critically on the availability of an appropriate radioactive isotope for a certain element. By emitting a specific decay particle or by just having excited states with the right spin and nuclear moments, radioactive isotopes overcome the limitations of ground states and stable nuclei. Hyperfine techniques (ME, PAC and $\beta$-NMR) rely on the interaction of the nuclear states, quadrupole and magnetic moments, with the electron density, electric field gradient (EFG) and magnetic hyperfine fields at the probe's location. By probing this information they provide nanoscopic scale information on defect structure, defect dynamics and electronic configuration. The EFG, in particular, provides information on the local charge density distribution and acts as a fingerprint of a specific defect trapped by the probe nuclei. These techniques are also used complementarily, e.g., while isomer and chemical shifts are only measured with ME, PAC is essentially temperature independent and a wider range of probe nuclei can be used.

\subsection{Emission channeling}

Since 1985 the emission channelling (EC) technique has been used at ISOLDE to determine with great accuracy the lattice site of dopant elements, by implanting their radioactive isotopes into single crystals. Upon decay, the nuclei emit charged particles, e.g., $\alpha, \beta^{+/}$, and conversion electrons, $\left(\mathrm{e}_{\mathrm{C}}\right)$, which, emerge from the crystal, experience channeling or blocking effects along low-index crystal directions [56]. EC makes use of the fact that near the principal crystalline axes the particle emission yield from the crystal surface is anisotropic, depending in a characteristic way on the lattice sites occupied by the emitter atoms. A clear advantage of EC over Rutherford Backscattering/Channeling $(\mathrm{RBS} / \mathrm{C})$ is the fact that any element, lighter or heavier than the host matrix, can be used without sensitivity loss, since only the existence of a radioactive isotope decaying with charged particles is required. A very good report of such type of work is presented in ref. [57], where alpha particles 
emitted from the decay of the short lived ${ }^{8} \mathrm{Li}$ are used to perform detailed lattice location studies of $\mathrm{Li}$ in elemental and compound semiconductors, to fluences even below $10^{12} \mathrm{~cm}^{-2}$.

During 1997, as a result of a collaboration with detector groups at CERN currently developing new readout technologies for high-energy particle physics, a position-sensitive electron detector $\left(3 \times 3 \mathrm{~cm}^{2}\right.$, $22 \times 22$ pixels) was successfully commissioned to perform EC experiments. Since then the EC technique has been boosted to high efficiency and improved angular resolution [58, 59]. In recent years, this technology got a further boost when much faster detectors - able to read up to $4 \mathrm{kHz}$ eventsrate - were developed. In 2007 one of these new detectors was implemented for EC experiments, opening up a panoply of new probing elements from where ${ }^{56} \mathrm{Mn}(2.6 \mathrm{~h}),{ }^{61} \mathrm{Co}(1.6 \mathrm{~h})$ and ${ }^{27} \mathrm{Mg}(9.5$ $\mathrm{min})$ are the most recent case studies [60].

During the last five years EC experiments focused on the lattice location of dopants and impurities in compound semiconductors $\mathrm{ZnO}$ [61 - 64], GaN [65, 66], AlN [67] and $\mathrm{Si}[68,69]$, as well as on $\mathrm{Ge}$. In the particular case of $\mathrm{Ge}$, besides the preferred substitutional sites, the following impurities were found to occupy the so-called bond-center (BC) site: $\operatorname{Er}[70]$, In [71], the transition metals $\mathrm{Fe}, \mathrm{Cu}$ and $\mathrm{Ag}$ [72], and $\mathrm{Sn}$ [73]. By investigating the formation energy of defect complexes with the help of density functional theory, the $\mathrm{BC}$ location was identified to be the preferred location for certain foreign substitutional atoms on interaction with a single vacancy. Hence, the impurity element relaxes to the $\mathrm{BC}$ site, opening an extra vacancy, and remaining in the mid-position of the two adjacent Ge vacancies, the so-called split-vacancy configuration.

Figure 4 shows a selected set of $\beta$ - emission channeling patterns resulting from the decay of ${ }^{111} \mathrm{Ag}$ implanted into Ge. The experimental data can only be explained by assuming that they result from a superposition of emission channelling patterns originated from $\mathrm{Ag}$ on substitutional $\left(\mathrm{Ag}_{\mathrm{S}}\right)$ and $\mathrm{BC}$ sites ( $\mathrm{Ag}_{\mathrm{BC}}$ ), with the best fit results obtained for $\sim 20 \%$ of ${ }^{111} \mathrm{Ag}_{\mathrm{S}}$ and $\sim 37 \%$ of ${ }^{111} \mathrm{Ag}_{\mathrm{BC}}$ sites. 


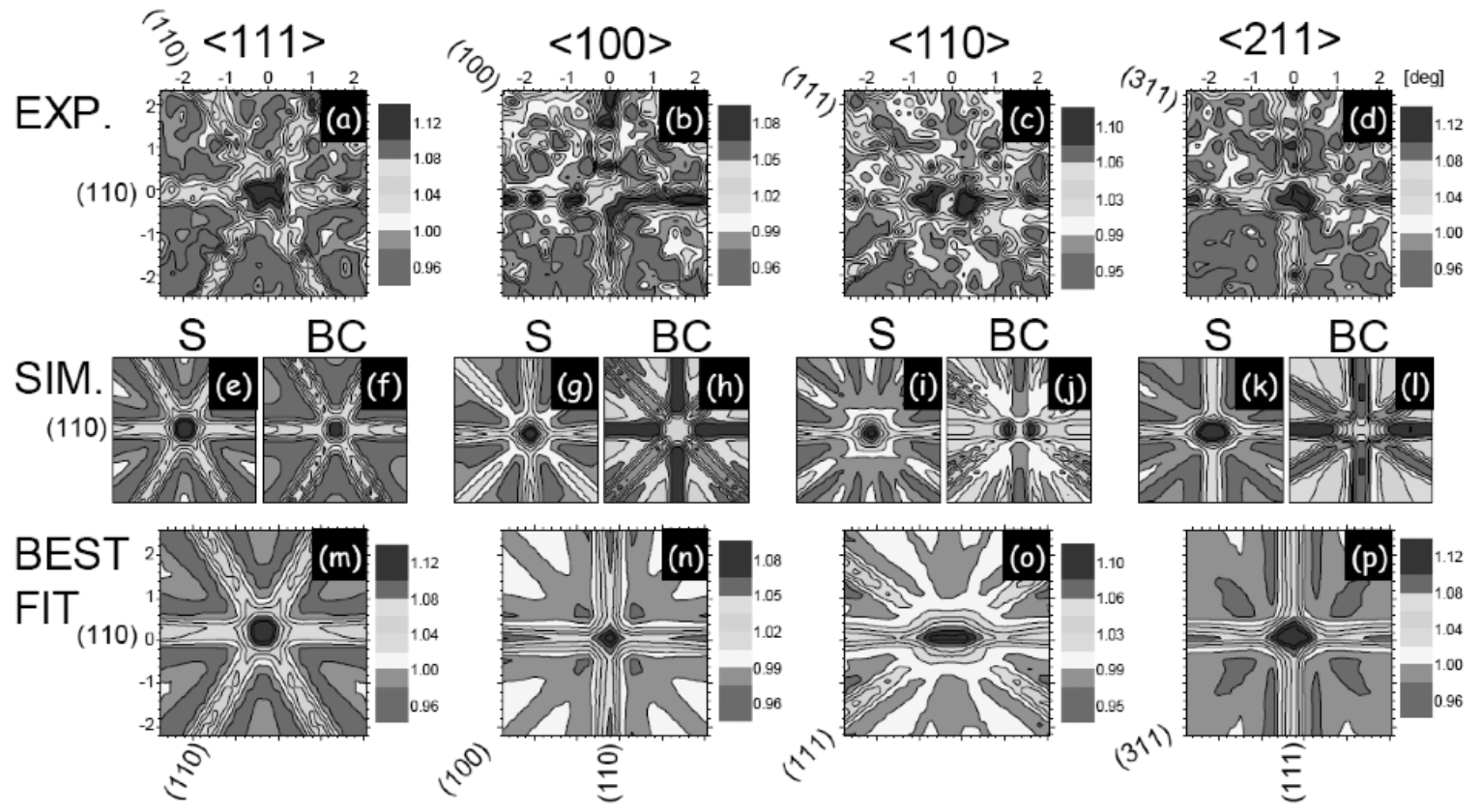

Figure 4: (a)-(d) Two-dimensional $\beta$ - emission channeling patterns from ${ }^{111} \mathrm{Ag}$ in $\mathrm{Ge}$ around the $<111>,<100>$, $<110>$, and $<211>$-axes, following $400{ }^{\circ} \mathrm{C}$ annealing in vacuum; simulated patterns for ${ }^{111} \mathrm{Ag}$ on the $\mathrm{S}$ site and on the BC site, respectively, are shown in panels (e), (f) for the $<111>$, (g), (h) for $<100>$, (i), (j) for $<110>$ and (k), (l) for $<211>$-axes; (m)-(p) are the best fits to the experimental patterns, consisting of a superposition of $\sim 20 \% \mathrm{~S}$ and $\sim 37 \%$ BC patterns. From Ref. [72]. Copyright (2009) by the American Physical Society. 


\subsection{Hyperfine interactions techniques}

\subsection{1 - Perturbed Angular Correlations - Solid State Physics}

In the late 1970s $\gamma-\gamma$ Perturbed Angular Correlation (PAC) was introduced at ISOLDE [17]. $\gamma-\gamma$ PAC is based on the observation of perturbations in the half-life time histogram of an intermediate state on a two - gamma quanta cascade. To extend the use of the technique to probe elements with highly converted electron cascades, $\mathrm{e}_{\mathrm{C}}-\gamma$ PAC was later introduced in the 1990s [74]. PAC allows the measurement of the local electrical field gradient (EFG) and the magnetic field that a probe nucleus experiences when embedded in matter, independent of its physical state, i.e., solids, liquid, amorphous and molecules can be studied with PAC. Initially the bulk of the experiments at ISOLDE concentrated on semiconductors and on metal surfaces which has already been extensively reviewed in the past [20 25, 27, 28, 75]. During the last couple of years, the PAC work at ISOLDE in the field of semiconductors has concentrated on experiments using the probes ${ }^{111} \mathrm{In},{ }^{111 \mathrm{~m}} \mathrm{Cd},{ }^{115} \mathrm{Cd},{ }^{117} \mathrm{Cd}$, and ${ }^{111} \mathrm{Ag}$ in the nitride semiconductors $\mathrm{AlN}, \mathrm{GaN}$, and $\mathrm{InN}$. The general aim is to better characterize the properties of $\mathrm{In}, \mathrm{Cd}$ and $\mathrm{Ag}$ impurities in nitrides, e.g., In is of relevance for understanding the technologically important ternary nitride $\operatorname{In}_{\mathrm{x}} \mathrm{Ga}_{1-\mathrm{x}} \mathrm{N}$ [76]. Another experiment is exploring the feasibility of PAC experiments with several rare earth probes in nitride semiconductors, using for this purpose a new concept of PAC spectrometer with all-digital electronics and data acquisition, aiming to optimize gamma selection on complicated decay cascades [77].

The selected PAC examples shown here have been chosen from two very different fields which have gained increasing importance over recent years; e.g., a solid state physics case where electronic phase transitions in manganites are regarded at the microscopic level and a biophysics example where PAC assesses the function and toxicity of metal ions in biological systems.

The first example concerns manganese oxides of the manganite type, where several degrees of freedom coexist leading to a rich phenomenology at the microscopic level where charge, magnetism and lattice coordinates can be coupled and ruled by doping. The particular case of the mixed valence compound $\operatorname{Pr}_{1-\mathrm{x}} \mathrm{Ca}_{\mathrm{x}} \mathrm{MnO}_{3}$ has an orthorhombic distorted perovskite structure and belongs to the class of multiferroic oxides, i.e., it shows a combination of ferroelectric and magnetic behaviour, which in this case is associated with the occurrence of $\mathrm{Mn}^{3+} / \mathrm{Mn}^{4+}$ valence charge order in the material. The PAC probe ${ }^{111 \mathrm{~m}} \mathrm{Cd}$ (48.5 min) was implanted into different $\operatorname{Pr}_{1-\mathrm{x}} \mathrm{Ca}_{\mathrm{x}} \mathrm{MnO}_{3}$ compounds, where it is incorporated on Ca sites $[78,79,80,81]$. The electrical field gradient experienced by the probe atoms was then measured as a function of temperature [Figure $5(\mathrm{~d})-(\mathrm{f})]$ across the charge order (CO) phase transition that was established from the magnetic susceptibility [Figure 5 (a)-(c)]. At low temperatures, 
in the $\mathrm{CO}$ regime, where the samples are ferroelectric or antiferroelectric, a slight temperature dependence of the main component $\mathrm{V}_{\mathrm{zz}}$ of the EFG is observed, which decreases slowly with the increasing temperature until a prominent discontinuity is reached and a sharp increasing jump in $\mathrm{V}_{\mathrm{zz}}$ occurs at a temperature $\mathrm{T}_{\mathrm{EDO}}$ close to, but clearly below the charge order temperature $\mathrm{T}_{\mathrm{CO}}$, followed again by a less sharp decrease. The soft temperature dependence of the EFG below $\mathrm{T}_{\mathrm{EDO}}$ was attributed to the onset of electrical dipole fluctuations at the probe site and $\mathrm{T}_{\mathrm{EDO}}$ itself is hence interpreted as the temperature where electrical dipole order is lost completely, which surprisingly occurs clearly below the temperature $\mathrm{T}_{\mathrm{CO}}$ where $\mathrm{Mn}^{3+} / \mathrm{Mn}^{4+}$ valence charge order itself is disappearing. In conclusion, the PAC measurements gave clear evidence for a new phase transition occurring below the charge order transition in $\operatorname{Pr}_{1-\mathrm{x}} \mathrm{Ca}_{\mathrm{x}} \mathrm{MnO}_{3}$ and it was interpreted in terms of a paraelectric to (anti)ferroelectric firstorder phase transition related to electric dipole ordering.

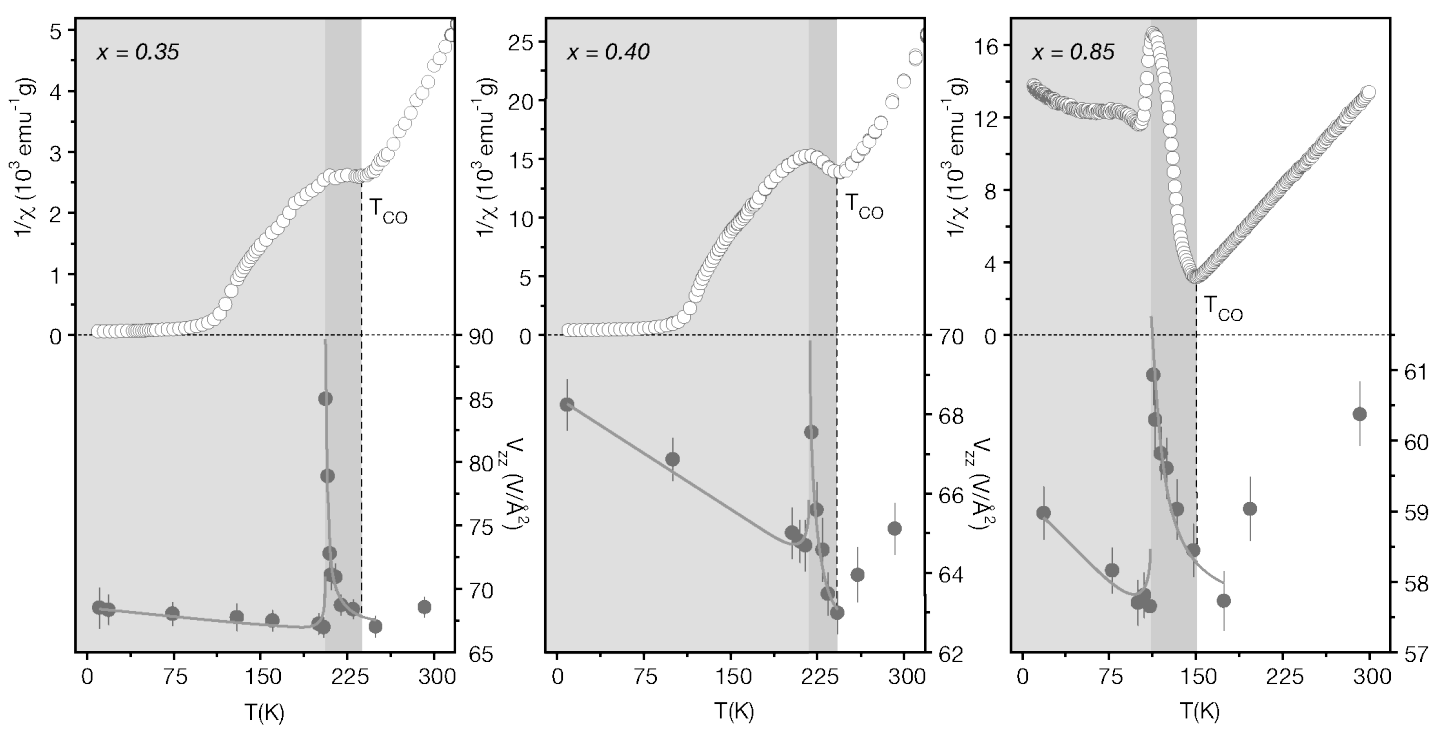

Figure 5: Top row: temperature dependence of the inverse magnetic susceptibility $1 / \chi$ for $\operatorname{Pr}_{1-\mathrm{x}} \mathrm{Ca}_{\mathrm{x}} \mathrm{MnO}_{3}$ samples with $\mathrm{x}=0.35$ (a), $\mathrm{x}=0.40$ (b), and $\mathrm{x}=0.85$ (c). Bottom row: temperature dependence of the electrical field gradient $\mathrm{V}_{\mathrm{zz}}$ seen by the radioactive ${ }^{111 \mathrm{~m}} \mathrm{Cd}$ nucleus and corresponding fits below the charge order transition using the Landau theory of phase transitions for $\mathrm{x}=0.35$ (d), $\mathrm{x}=0.40$ (e), and $\mathrm{x}=0.85$ (f). Reprinted with permission from Ref. [79]. Copyright 2008, American Physical Society. 


\subsection{2 - Perturbed Angular Correlations - Biophysics}

Since the beginning of the 1990s both biophysics and medical applications have embraced the ISOLDE research program. But, while biophysics has remained steadily active, medical applications mainly concerning the production of radioisotopes for small-scale clinical studies [82], e.g., in cancer therapy - have declined in the past few years. This tendency seems now to have been reversed, with the submission of a new proposal to resume this activity at the upgraded HIE-ISOLDE facility [83].

Biophysics studies using the PAC technique with the probe nuclei ${ }^{199 \mathrm{~m}} \mathrm{Hg}(43 \mathrm{~min})$ and ${ }^{111 \mathrm{~m}} \mathrm{Cd}$ (48 min) generally aim to identify the binding sites, ligands, and dynamic interactions of probe atoms attached to large biomolecules under specific conditions such as temperature, ambient solution, $\mathrm{pH}$, etc, as partially reviewed by Hemmingsen [84] and Chain [ 85]. For that purpose, the radioisotopes are implanted in ice held at liquid nitrogen temperature so that, after removing the beam catcher from the vacuum chamber, the radioactive probes are directly available for biochemical processing in aqueous solution using a small chemistry lab located on-site. PAC spectra are then typically recorded by 6detector setups [86] that are shared with the materials science community. Initially, in the work of Butz and Tröger [87 - 89], the main subjects were blue copper proteins doped with radioactive ${ }^{199 \mathrm{~m}} \mathrm{Hg}$, while more recently the study of Hg-binding peptides and Zn-binding proteins emerged [90 - 92], both with the general aim to assess the function and toxicity of metal ions in biological systems.

Figure 6 shows the Fourier transforms of the ${ }^{199 m} \mathrm{Hg}$ PAC spectra corresponding to the $\mathrm{pH}$ titration of a solution containing the peptide TRI L9C and $\mathrm{Hg}(\mathrm{II})$ ions (stable $\mathrm{Hg}$ carriers plus ${ }^{199 \mathrm{~m}} \mathrm{Hg}$ ) at a peptide/ $\mathrm{Hg}$ (II) ratio of 12:1. While only one nuclear quadrupole interaction type (characterized by one single frequency triplet) is found for the experiment at $\mathrm{pH} 6.5$, upon increasing the $\mathrm{pH}$ of the solution another set of signals appears in the PAC spectra, which then remains responsible for the major part $(90 \%)$ of the signal at $\mathrm{pH}$ 8.7. At this $\mathrm{pH}$ value, the fitted PAC parameters indicate the formation of a complex with a trigonal-planar $\left[\mathrm{Hg}(\mathrm{TRI} \text { L9C })_{3}\right]$ coordination geometry, while the fitted PAC parameters for the species at low $\mathrm{pH}$ compare reasonably well with published data for linear [Hg(TRI L9C $\left.)_{2}\right]$ coordination geometry, supporting the formation of a dithiolate- $\mathrm{Hg}(\mathrm{II})$. The results support the existence of a dithiolate- $\mathrm{Hg}$ (II) complex encapsulated within a three-stranded coiled coil and a stepwise aggregation- deprotonation mechanism. For the future, it is planned to extend the ISOLDE biophysics experiments to in vivo studies, i.e., by introducing the PAC probes into living plants. 


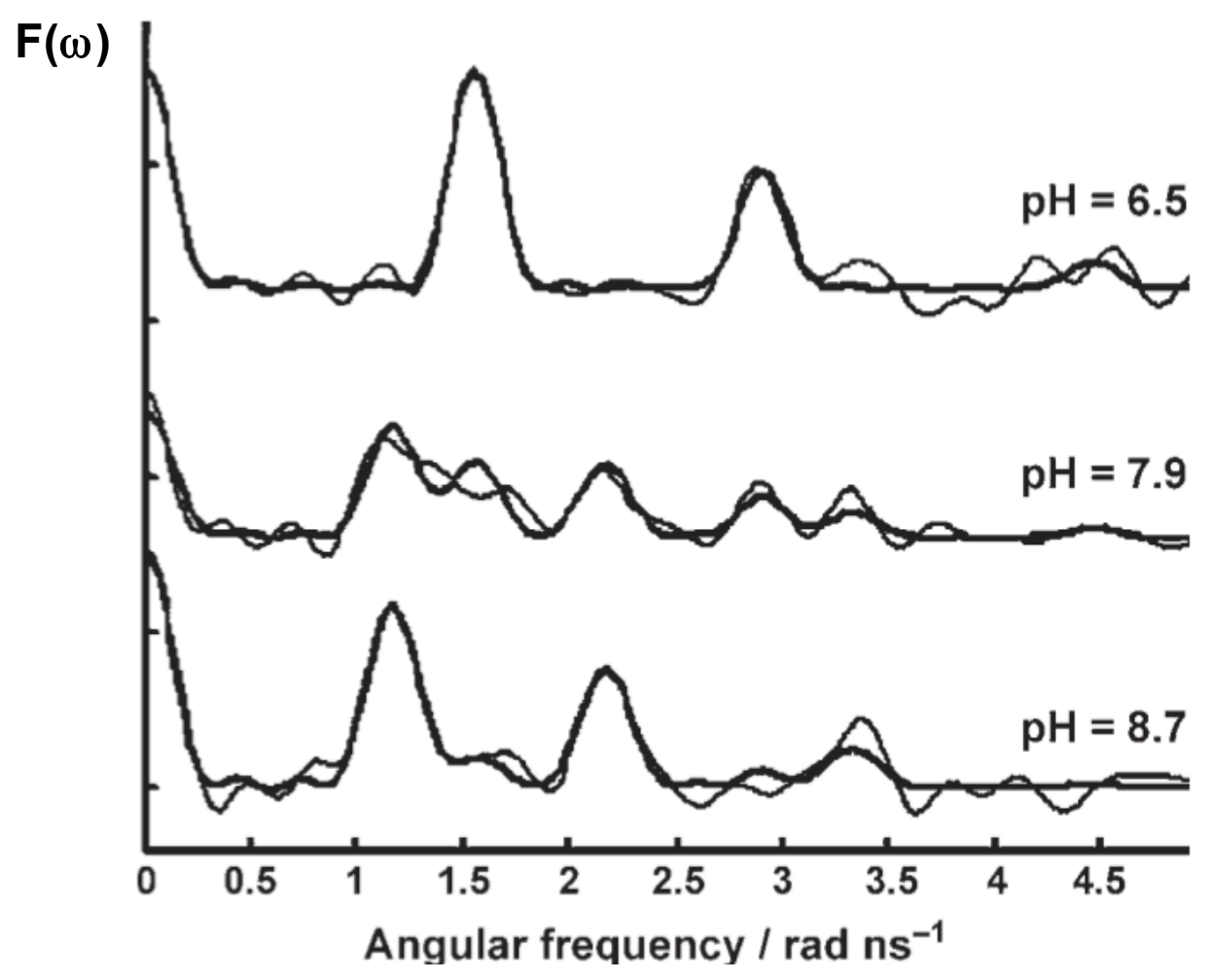

Figure 6: ${ }^{199 \mathrm{~m}} \mathrm{Hg}$ PAC spectra of solutions containing TRI L9C $(125-130 \mathrm{~mm})$ and $\mathrm{HgCl} 2(10.8 \mathrm{~mm})$ at different $\mathrm{pH}$ values. The thin lines represent the Fourier transform $(\mathrm{F}(\omega)$ in arbitrary units ) of the experimental data and the bold lines represent the fit. Reprinted with permission from Ref. $\left[{ }^{90}\right]$. Copyright 2008, Wiley VCH Verlag.

\subsection{3 - Mössbauer Effect}

By yielding information on the charge state of probe atoms and on the materials electrical field gradients and magnetic fields interacting in their neighbourhood, Mössbauer spectroscopy is the oldest and the only worldwide-known hyperfine technique using radioisotopes in Materials Science. This is mainly due to the well-known ${ }^{57 *} \mathrm{Fe}(14.4 \mathrm{keV}, 98 \mathrm{~ns})$ isomeric state, i.e., an optimum case to be resonantly excited from decay of the long-lived ${ }^{57} \mathrm{Co}(271 \mathrm{~d})$ gamma-ray source. The fact that $2.2 \%$ of the isotopic composition of natural iron is made of ${ }^{57} \mathrm{Fe}$, further guarantees that ${ }^{57} \mathrm{Fe} /{ }^{57} \mathrm{Co}$ Mössbauer experiments remain preponderant in applied materials research.

To extend applications and the number of available probe elements for Mössbauer spectroscopy, two independent and complementary ways are investigated, both requiring the use of large-scale facilities, which aim to work with no radioactive sources or with short-lived isotopes. In 
the case of no use of radioactive isotopes, the excitation gamma quanta are produced by proper wavelength filtering of synchrotron radiation to induce the nuclear resonant excitation, as had been proposed in the late 1950s and pointed out in ref. [93]. The advent of powerful synchrotron facilities for multipurpose use in materials, chemical and biophysics research, provides today a fertile ground for developing such techniques with great potential [94]. In the alternative and complementary case, highly pure beams of short-lived isotopes, produced on-line at radioactive ion beam facilities, are used to increase the number of available probe elements. For this reason, Mössbauer spectroscopy was introduced at ISOLDE in the late 1970s and is today being applied to new and exotic ME experiments as was recently reviewed by Weyer [95]. Studies of the structure and electronic states of impurityvacancy complexes in III-V semiconductors and of Sb doping of Si-based semiconductors such as SiGe alloys have been performed at ISOLDE, by using the first excited state at $24 \mathrm{keV}$ in ${ }^{119} \mathrm{Sn}$, which is obtained either by the decay of the long-lived ${ }^{119} \mathrm{Sb}(38.2 \mathrm{~h})$ or by decay of the short-lived ${ }^{119} \mathrm{In}(18$ min) isotopes [96]. Such studies have been particularly extended to the wide band gap GaN semiconductor, by implanting ${ }^{119} \mathrm{Cs}$ which decays through the ${ }^{119} \mathrm{Xe} \rightarrow{ }^{119} \mathrm{I} \rightarrow{ }^{119} \mathrm{Te} \rightarrow{ }^{119} \mathrm{Sb}$ isobaric chain to the Mössbauer ${ }^{119} \mathrm{Sn}$ nucleus. Since the recoil energies $(>50 \mathrm{eV})$ are large enough to place, at the end of the decay chain, ${ }^{119} \mathrm{Sb}$ in $\mathrm{Ga}$ and $\mathrm{N}$ sites, this technique enables the measurement of isomer shifts, i.e., the electron densities, for Sn donors and acceptors on Ga and N sites, respectively [97].

In 1996, the technique received a considerable boost with the introduction of Mn laser ionisation sources at ISOLDE which made it possible to obtain high-intensity isotopically clean beams of the short-lived (1.5 min) ${ }^{57} \mathrm{Mn}$ that decays into the well-known ${ }^{57 *} \mathrm{Fe}(98 \mathrm{~ns})$ level. In comparison to ${ }^{57 *} \mathrm{Fe}$ Mössbauer studies which use long-lived ${ }^{57} \mathrm{Co}$ sources, both in absorption and emission mode, the short half-life of ${ }^{57} \mathrm{Mn}$ in combination with the high purity- high - intensity beam available at ISOLDE (up to $2 \times 10^{8}$ at/s corresponding to $\sim 30 \mathrm{pA}$ ) allows for several orders of magnitude faster data acquisition, making it possible to record hundreds of Mössbauer spectra per day. This is a particularly revealing example of the uniqueness and versatility of ISOLDE, far in the forefront of worldwide radioactive ion beam facilities. Since then, ${ }^{57} \mathrm{Mn} \rightarrow{ }^{57} \mathrm{Fe}$ Mössbauer experiments have been undertaken in a large variety of semiconductors and oxides, with a focus on $\mathrm{Si}, \mathrm{Si}_{\mathrm{x}} \mathrm{Ge}_{1-\mathrm{x}}$ [98], diamond [99] and especially $\mathrm{ZnO}[100$ - 103] in recent years.

The example that will be briefly presented here relates to the long standing problematic of local magnetism at dilute $\mathrm{Fe}$ atoms in ion-implanted $\mathrm{ZnO}[100]$.

Figure 7 shows ${ }^{57} \mathrm{Mn} \rightarrow{ }^{57} \mathrm{Fe}$ Mössbauer spectra, which were recorded during the implantation of low fluences $\left(<10^{12} \mathrm{~cm}^{-2}\right)$ of ${ }^{57} \mathrm{Mn}$ at various temperatures. Below $600 \mathrm{~K}$ the Mössbauer spectra clearly show a pronounced sextet resulting from magnetic interaction of $\mathrm{Fe}^{3+}$, on which two doublets D2 and 
D3 are superimposed, resulting from quadrupole-split $\mathrm{Fe}^{2+}(\mathrm{Zn})$ and interstitial $\mathrm{Fe}_{\mathrm{i}}$, respectively. In addition two distributions (Dist. II and Dist. III) of magnetic signals were seen. For higher implantation temperatures the magnetic interaction gradually disappears until $770 \mathrm{~K}$ when only the weakly split D2 quadrupole doublet remains, which was interpreted as substitutional $\mathrm{Fe}^{2+}(\mathrm{Zn})$ on $\mathrm{Zn}$ sites. However, from these data alone, it was not possible to determine whether ferromagnetism or paramagnetism was responsible for the observed magnetic sextet [100]. The same group has recently shown, by means of measuring the angular dependence of the Mössbauer spectra in an external magnetic field, that the coupling is clearly paramagnetic and ferromagnetism could be ruled out [103], which obviously reduces the perspectives for $\mathrm{ZnO}: \mathrm{Fe}$ acting as a true dilute magnetic semiconductor. 


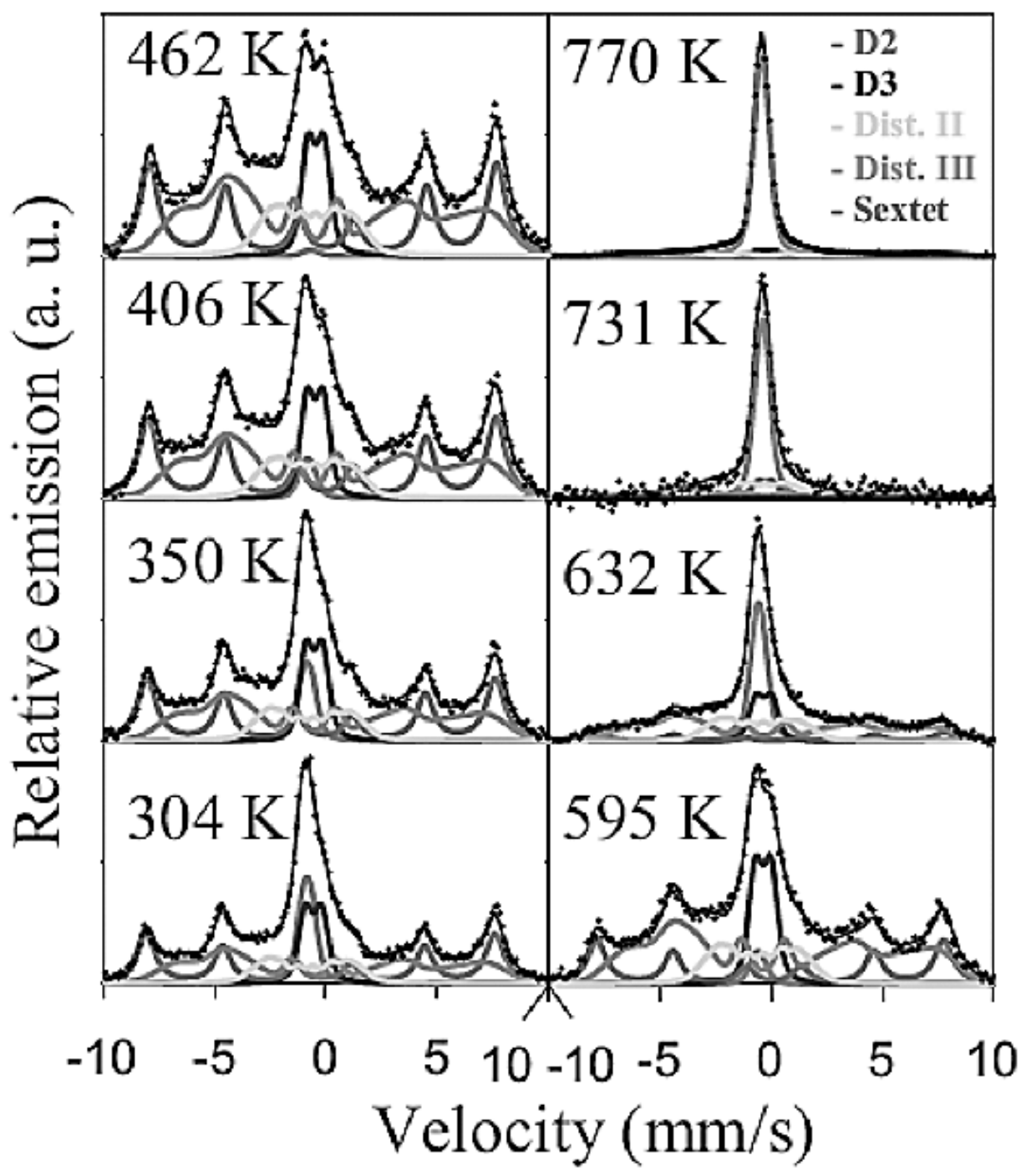

Figure 7: On-line Mössbauer spectra from the ${ }^{57} \mathrm{Mn} \rightarrow{ }^{57} \mathrm{Fe}$ decay obtained in $\mathrm{ZnO}$ as a function of implantation temperature. The solid black lines are fits to the data points resulting from the superimposition of the various contributions shown in colour, as is explained in the text. Reprinted with permission from Ref. [100]. Copyright 2007, American Institute of Physics. 


\section{4 - Conclusions and Perspectives}

The interface between nuclear and solid state physics has always been a fertile ground for discovering new phenomena and attractive applications. ISOLDE is a place of dynamic interaction between Solid State and Biophysics researchers on one side and Nuclear and Atomic physicists and their state-of-theart techniques on the other. The permanent R\&D program on beam variety, purity and energies guarantees that ISOLDE remains in the forefront of thick target technologies for the production of radioactive isotopes. The combination of these factors assures a bright future for ISOLDE's "exotic", still unique, physics in materials research as well as encouraging the development of complementary facilities, which could increase the availability of beam time, quite tight today due to the great demand by many different groups from all branches of physics.

\section{Acknowledgments}

We thank V. Amaral, J.P. Araújo, S. Decoster, M. Deicher, H. Gunnlaugsson, L. Hemmingsen, A.M.L. Lopes, R. Magerle, G. Weyer, Th. Wichert and H. Wolf for valuable discussions and for providing figures from their original works. This work was supported by the Portuguese Foundation for Science and Technology through grants PTDC/FIS/66262/2006 and CERN-FP-116320-2010, and by the BMBF German research program under contracts 05KK7TS2 and 05K10TS2. 


\section{References}

1. Lindroos, M.: in Proceedings of European Particle Accelerator Conference 2004, Lucerne, Switzerland, EPAC, European Physical Society Accelerator Group, 2004, p.45.

2. Hagebø, E., Hoff, P., Jonsson, O.C., Ravn, H.L.: New production systems at ISOLDE, Nucl. Instr. and Meth. B70, 107 (1992).

3. Kugler, E.: The ISOLDE facility at the CERN PS Booster, Nucl. Instr. and Meth. B79, 322 (1993).

4. Jonson, B., Richter, A.: More than three decades of ISOLDE physics, Hyp. Int. 129, 1 (2000).

5. Jonson, B., Riisager, K.: The ISOLDE facility, Scholarpedia, 5, 9742 (2010).

6. Jading, Y., Catherall, R., Fedoseyev, V.N., Jokinen, A., Jonsson, O.C., Kautzsch, T., Klöckl, I., Kratz, K.-L., Kugler, E., Lettry, J., Mishin, V.I., Ravn, H.L., Scheerer, F., Tengblad, O., Van Duppen, P., Walters, W.B., Wöhr, A., and the ISOLDE Collaboration : Production of radioactive $\mathrm{Ag}$ ion beams with a chemically selective laser ion source, Nucl. Instr. and Meth. B126, 76 (1997).

7. Jokinen, A., Evensen, A-H., Kugler, E., Lettry, J., Ravn, H., Van Duppen, P., Erdman, N., Jading, Y., Köhler, S., Kratz, K-L., Trautman, N., Wöhr, A., Fedoseyev, V.N., Mishin, V.I., Tikhonov, V., and ISOLDE-collaboration : Selective laser ionization of radioactive Ni-isotopes, Nucl. Instr. and Meth. B126, 95 (1997).

8. Fedoseyev, V.N., Bätzner, K., Catherall, R., Evensen, A.H.M., Forkel-Wirth, D., Jonsson, O.C., Kugler, E., Lettry, J., Mishin, V.I., Ravn, H.L., Weyer, G., and the ISOLDE Collaboration : Chemically selective laser ion source of manganese, Nucl. Instr. and Meth. B126, 88 (1997).

9. Lettry, J., Catherall, R., Focker, G. J., Jonsson, O. C., Kugler, E., Ravn, H., Tamburella, C., Fedoseyev, V., Mishin, V. I., Huber, G., Sebastian, V., Koizumi, M., Köster, U.: Recent Developments of the ISOLDE Laser Ion-Source, Rev. Sci. Instrum. 69, 761(1998).

10. Habs, D. , et al., The REX-ISOLDE project, Hyp. Int. 129, 43(2000).

11. Voulot, D., Wenander, F., Piselli, E., Scrivens, R., Lindroos, M., Jeppesen, H.B., Fraile, L.M., Sturm, S., Delahaye, P., and the REX-ISOLDE collaboration : Radioactive beams at REXISOLDE: Present status and latest developments, Nucl. Instr. Meth. B266, 4103 (2008).

12. Frånberg, H., Delahaye, P., Billowes, J., Blaum, K., Catherall, R., Duval, F., Gianfrancesco, O., Giles, T., Jokinen, A., Lindroos, M., Lunney, D., Mane, E., Podadera, I.: Off-line commissioning of the ISOLDE cooler, Nucl. Instr. Meth. B266, 4502 (2008).

13. Wenander, F.: Charge breeding of radioactive ions with EBIS and EBIT, Jour. Instr. 5, C10004 (2010) 
14. Haas, H., Lindroos, M., and the ISOLDE Collaboration : Beam energy boosting for experiments at ISOLDE using a high-voltage platform, Nucl. Instr. and Meth. B126, 250 (1997).

15. Hemmingsen, L., Stachura, M., Bissell, M.L., Georgiev, G., Gottberg, A., Johnston, K., Kowalska, M., Kreim, K., Luczkowski, M., Neyens, G., Yordanov, D.T., Zeitz, W.D.: Beta-NMR as a novel technique for biological applications, CERN-INTC-2010-015, INTC-I-088, http://cdsweb.cern.ch/record/1232580/files/INTC-I-088.pdf.

16. http://hie-isolde.web.cern.ch/ and documents therein.

17. Haas, H., Menninger, M.: Electric field gradient for indium in As, Sb, and Bi, Hyp. Int. 9, 277 (1981).

18. Haas, H.: Proc. Workshop on the Production and Use of Intense Radioactive Beams at the ISOSPIN Lab., ed. J.G. Garret (Oak Ridge, 1992) p. 83.

19. Haas, H., and the ISOLDE collaboration : Condensed matter physics with radioactive ion beams, Nucl. Instr. Meth. B107, 349 (1996).

20. Forkel-Wirth, D.: Radioactive isotopes in solid state physics, Nucl. Instr. Meth. B126, 396 (1997).

21. Wichert, Th., Deicher, M.: Studies of semiconductors, Nuclear Physics A693, 327 (2001).

22. Forkel-Wirth, D.: Radioactive ion beams in solid state physics, Phil. Trans. R. Soc. Lond. A356, 2137 (1998).

23. Forkel-Wirth, D.: Exploring solid state physics properties with radioactive isotopes, Rep. Prog. Phys. 62, 527 (1999).

24. Deicher, M., and the ISOLDE collaboration : Applications of radioactive ion beams to solid-state physics, Eur. Phys. J. A15, 275 (2002).

25. Audit to Solid State Physics at ISOLDE, CERN-INTC-2002-006 INTC-O-008, 30 January 2002, http://cdsweb.cern.ch/record/536172/files/intc-o-008.pdf

26. Deicher, M.: Radioactive isotopes in solid state physics, Europhysics News 33, 3 (2002).

27. Deicher, M., Weyer, G., Wichert, Th., and the ISOLDE collaboration : Solid state physics at ISOLDE, Hyperfine Interactions 151.152, 105 (2003).

28. Wichert, Th.: Semiconductor studies by radioactive probe atoms, Physica B 326 (2003) 105.

29. Groh, J. and v. Hevesy, G.: Die Selbstdiffusionsgeschwindigkeit des geschmolzenen Bleis, Ann. Phys. 63, 85 (1920) and Ann. Phys. 65, 216 (1921).

30. Horz, M., Gustin, W., Scharwaechter, P., Frank, W., and the ISOLDE Collaboration : Diffusion of Transition Metals in Amorphous Silicon and Germanium, Def. Diff. Forum 143-147, 729 (1997). 
31. Haas, H., Biersack, J.P., Fink, D., Grawe, H., Lindroos, M., and Nishimura, K.: Diffusion in highly immiscible systems, CERN-ISC-94-29 ; ISC-I-15. - 1994. - 6 p.

32. Wolf, H., Wagner, F. and Wichert, Th.: Anomalous Diffusion Profiles of Ag in CdTe due to Chemical Self-Diffusion, Phys. Rev. Lett. 94, 125901 (2005).

33. Wolf, H., Wagner, F., and Wichert, Th.: The Role of Intrinsic Defects for the Diffusion of Ag and $\mathrm{Cu}$ in CdTe, Defect and Diffusion Forum 237-240, 491 (2005).

34. Wagner, F., Wolf, H., and Wichert, Th.: Proc. 1. Int. Conf. on Diffusion in Solids and Liquids, ed. A. Öchsner, J. Grácio, F. Barlat (University of Aveiro, 2005) 799.

35. Wolf, H., Wagner, F., Kronenberg, J., Wichert, Th., Grill, R., Belas, E., and the ISOLDE collaboration : Drift-diffusion of highly mobile dopants in CdTe, Diffusion Fundamentals 8, 3 (2008).

36. Wichert, Th., Wolf, H., Guan, Z., Li, X.: Investigation of nanocrystalline materials using radioactive isotopes, Zeitschrift fur Physikalische Chemie 222, 355 (2008).

37. Wolf, H., Kronenberg, J., Wagner, F., Wichert, Th., and the ISOLDE collaboration : Prerequisites for the formation of unusual diffusion profiles in II-VI semiconductors, Physica Status Solidi B, 1405247 (2010).

38. Koskelo, O., Pusa, P., Räisänen, J., Köster, U., Riihimäki, I.: Diffusion of beryllium in Ge and SiGe alloys, Journal of Applied Physics 103, 73513 (2008).

39. Koskelo, O., Räisänen, J., Köster, U., Riihimäki, I.: Migration kinetics of ion-implanted beryllium in glassy carbon, Diamond and Related Materials 17,1991 (2008).

40. Riihimäki, I., Virtanen, A., Kettunen, H., Pusa and P., Räisänen, J.: Diffusion properties of Ga in $\mathrm{Si}_{1-\mathrm{x}} \mathrm{Ge}_{\mathrm{x}}$ alloys, Journal of Applied Physics 104, 123510 (2008).

41. Koskelo, O., Räisänen, J., Tuomisto, F., Sadowski, J., and the ISOLDE collaboration : The effect of material growth technique on ion implanted Mn diffusion in GaAs, Semiconductor Science and Technology 24, 045011 (2009).

42. Alnatt, A.R., Lidiard, A.B.: Atomic transport in solids, (Cambridge University Press, Cambridge, 2003).

43. Deicher, M., Collins, G.S., Gerten, R., Johnston, K., Kronenberg, J., Türker, M., Wagner, F., Wichert, Th., Wolf, H., Zacate, M.O.: Radiotracer diffusion in semiconductors and metallic compounds using short-lived isotopes, CERN-INTC-2009-013 / INTC-P-261 19/01/2009, http://cdsweb.cern.ch/record/1156122/files/INTC-P-261.pdf

44. Broser, I., Franke, K.-H.: Erzeugung 'Ultraroter' Kupferzentren in ZnS durch Kernzerfall von Zn65, J. Phys. Chem. Sol. 26, 1013 (1965). 
45. Petersen, J.W., and Nielsen, J.: Identification of band-gap states by deep level transient spectroscopy on radioactive probes: The case of Au and Pt in silicon, Appl. Phys. Lett. 56, 1122 (1992).

46. Gwilliam, R., Sealy, B.J., and Vianden, R.: The electrical and radioactive assessment of the transmutation doping of GaAs following implantation by ${ }^{111}$ In, Nucl. Instr. and Meth. B 63, 106 (1992).

47. Bollmann, J., Wienecke, M., Röhrich, J., and Kerkow, H.: Doping and compensation phenomena of Ag in CdTe, J. Crystal Growth 159, 384 (1996).

48. Wienecke, M., Bollmann, J., Röhrich, J., Maass, K., Reinhold, B., Forkel-Wirth, D.: Transmutation doping of wide-bandgap II-VI compounds, J. Crystal Growth 161, 82 (1996).

49. Daly, S.E., Henry, M.O., Freitag, K., and Vianden, R.: Radioactive isotopes for photoluminescence spectroscopy- ${ }^{111}$ In in silicon, J. Phys. Cond. Matt. 6, L643 (1994).

50. Burchard, A. et al., Gold and Platinum in Silicon-Isolated Impurities and Impurities Complexes, CERN/ISC 96-26, ISC/P81, ADD.1, (1996).

51. Magerle, R., Burchard, A., Deicher, M., Kerle, T., Pfeiffer, W., and Recknagel, E.: Radioactive Isotopes in Photoluminescence Experiments: Identification of Defect Levels, Phys. Rev. Lett.75, 1594 (1995).

52. Achtziger, N., et al.: Combined Electrical, Optical and Nuclear Investigations of Impurities and Defects in II-IV Semiconductors, CERN/ISC 92-35, ISC/P35 (1992).

53. Johnston, K., Henry, M. O., McCabe, D., McGlynn, E., Dietrich, M., Alves, E., Xia, M.: Identification of donor-related impurities in $\mathrm{ZnO}$ using photoluminescence and radiotracer techniques, Phys. Rev. B 73, 165212 (2006).

54. Karaiskaj, D., Stotz, J. A. H., Meyer, T., Thewalt, M. L. W., and Cardona, M.: Impurity Absorption Spectroscopy in ${ }^{28} \mathrm{Si}$ : The Importance of Inhomogeneous Isotope Broadening, Phys. Rev. Lett. 90, 186402(2003).

55. Steger, M., Yang, A., Sekiguchi, T., Saeedi, K., Thewalt, W., Henry, M. O., Johnston, K., Alves, E., Wahl, U., Riemann, H., Abrosimov, N. V., Churbanov, M. F., Gusev, A. V., Kaliteevskii, A. K., Godisov, O. N., Becker, P., and Pohl, H.-J.: Isotopic fingerprints of Pt-containing luminescence centers in highly enriched ${ }^{28} \mathrm{Si}$, Phys. Rev. B 81, 235217 (2010).

56. Hofsass, H. and Lindner, G.: Emission channeling and blocking, Phys. Rep. 201, 121 (1991).

57. Wahl, U. and the ISOLDE Collaboration : Emission channeling studies of Li in semiconductors, Phys. Rep. 280, 145 (1997).

58. Weilhammer, P., Nygård, E., Dulinski, W., Czermak, A., Djama, F., Gadomski, S., Roe, S., 
Rudge, A., Schopper, F., and Strobel, J.: Si pad detectors, Nucl. Instr. and Meth. A 383, 89 (1996).

59. Wahl, U., Correia, J.G., Czermak, A., Jahn, S.G., Jalocha, P., Marques, J.G., Rudge, A., Schopper, F., Soares, J.C., Vantomme, A., Weilhammer, P., and the ISOLDE collaboration : Position-sensitive Si pad detectors for electron emission channeling experiments, Nucl. Instr. and Meth. A 524, 245 (2004).

60. Amorim, L., Araújo, J.P., Bharuth-Ram, K., Correia, J.G., Darakchieva, V., da Silva, M.R., Decoster, S., Hofsäss, H., Nagl, M., Pereira, L., Vantomme, A., Vetter, U., and Wahl, U.: EMISSION CHANNELING LATTICE LOCATION EXPERIMENTS WITH SHORT-LIVED ISOTOPES， CERN-INTC-2010-012 / INTC-P-218-ADD-1, http://cdsweb.cern.ch/record/1232263/files/ INTC-P-218-ADD-1.pdf

61. Wahl, U., Rita, E., Correia, J.G., Alves, E., Soares, J.C., and the ISOLDE collaboration : Direct evidence for As as a Zn-site impurity in ZnO, Phys. Rev. Lett. 95, 215503 (2005).

62. Wahl, U., Rita, E., Correia, J.G., Agne, T., Alves, E., Soares, J.C., and the ISOLDE collaboration : Lattice sites of implanted $\mathrm{Cu}$ and $\mathrm{Ag}$ in $\mathrm{ZnO}$, Superlattices and Microstructures 39 (2006) 229.

63. Wahl, U., Correia, J.G., Decoster, S., Mendonça, T.: Direct evidence for Sb as a Zn site impurity in $\mathrm{ZnO}$, Appl. Phys. Lett. 94, 261901 (2009).

64. Wahl, U., Correia, J.G., Decoster, S., Mendonça, T.: Lattice location of the group V elements As and $\mathrm{Sb}$ in $\mathrm{ZnO}$, Physica B 404, 4803 (2009).

65. De Vries, B., Vantomme, A., Wahl, U., Correia, J.G., Araújo, J.P., Lojkowski, W., Kolesnikov, D., and the ISOLDE collaboration : Lattice site location and annealing behaviour of $\mathrm{Ca}$ and $\mathrm{Sr}$ implanted GaN, Journal of Applied Physics 100, 023531 (2006).

66. Wahl, U., Correia, J.G., Araújo, J.P., Rita, E., and Soares, J.C., Amphoteric arsenic in GaN, Appl. Phys. Lett. 90, 181934 (2007).

67. Vetter, U., Gruber, J.B., Nijjar, A.S., Zandi, B., Öhl, G., Wahl, U., De Vries, B., Hofsäss, H., Dietrich, M., and the ISOLDE collaboration : Crystal field analysis of $\mathrm{Pm}^{3+}(4 f 4)$ and $\mathrm{Sm}^{3+}(4 f$ 5) and lattice location studies of ${ }^{147} \mathrm{Nd}$ and ${ }^{147} \mathrm{Pm}$ in w-AlN, Phys. Rev. B 74, 205201 (2006).

68. Wahl, U., Correia, J.G., Rita, E., Araújo, J.P., Soares, J.C., and the ISOLDE collaboration : Lattice sites of implanted Fe in Si, Physical Review B 72, 014115 (2005).

69. Wahl, U., Correia, J.G., Rita, E., Araújo, J.P., Soares, J.C., and the ISOLDE collaboration : Fe and $\mathrm{Cu}$ in Si: lattice sites and trapping at implantation-related defects, Nucl. Instr. and Meth. B 253, 167 (2006).

70. Decoster, S., De Vries, B., Vantomme, A., Wahl, U., Correia, J.G.: Experimental evidence of 
tetrahedral interstitial and bond-centered Er in Ge, Appl. Phys. Lett. 93, 141907 (2008).

71. Decoster, S., De Vries, B., Wahl, U., Correia, J.G., and Vantomme, A.: Lattice location study of implanted In in Ge, J. Appl. Phys. 105, 083522 (2009).

72. Decoster, S., Cottenier, S., De Vries, B., Emmerich, H., Wahl, U., Correia, J.G., Vantomme, A.: Transition metal impurities on the bond-centered site in Ge, Phys. Rev. Lett. 102 (2009) 065502.

73. Decoster, S., Cottenier, S., Wahl, U., Correia, J.G., and Vantomme, A.: Lattice location of ion implanted Sn and Sn-related defects in Ge, Physical Review B 81, 155204 (2010).

74. Correia, J.G., Haas, H, Marques, J.G., Melo, A.A, Soares, J.C., and the ISOLDE Collaboration : ${ }^{73} \mathrm{Ge}$ : a new high resolution PAC probe, Hyperfine Interactions 80, 1321 (1993).

75. Deicher, M., and the ISOLDE collaboration : Characterization of defects in semiconductors using radioactive isotopes, Physica B 389, 51 (2007).

76. Alves, E., Araújo, J. P., Barbosa, M., Correia, J. G., Johnston, K., Keßler, P., Lopes, A. L., Lorenz, K., Magalhães, S., Marques, J. G., Niederhausen, J., and Vianden, R.: The role of In in III-nitride ternary semiconductors, http://cdsweb.cern.ch/record/1132590/files/ INTC-P-251.pdf

77. Vetter, U., Wahl, U., Correia, J.G., Johnston, K., Nagl, M., Uhrmacher, M., Hofsäss, H., Crystal field investigations of rare earth doped wide band gap semiconductors, http://cdsweb.cern.ch/record/1156114/files/INTC-P-256.pdf

78. Araújo, J.P., Lopes, A.M.L., Rita, E., Correia, J.G., Amaral, V.S., Wahl, U., and the ISOLDE Collaboration, Local probe studies on oxides using radioactive isotopes, Mat. Sci. For. 514, 1593 (2006).

79. Lopes, A.M.L., Araujo, J.P., Amaral, V.S., Correia, J.G., Tomioka, Y., and Tokura, Y.: New phase transition in the $\operatorname{Pr}_{1-\mathrm{x}} \mathrm{Ca}_{\mathrm{x}} \mathrm{MnO}_{3}$ system: Evidence for electrical polarization in charge ordered manganites, Phys. Rev. Lett. 100, 155702 (2008).

80. Lopes, A.M.L., Araujo, J.P., Mendonca, T.M., Amaral, J.S., Pereira, A.M., Tavares, P.B., Amaral, V.S., Correia, J.G.: Magnetic Hyperfine Field Study in the $\operatorname{Pr}_{1-\mathrm{x}} \mathrm{Ca}_{\mathrm{x}} \mathrm{MnO}_{3} \mathrm{System}_{\text {, }}$ Journal of Non-Crystalline Solids 354, 5315 (2008).

81. Lopes, A.M.L., Araújo, J.P., Ramasco, J.J., Rita, E., Amaral, V.S., Correia, J.G., Suryanarayanan, R., and the ISOLDE Collaboration : Free percolative phase transition on ferromagnetic insulator manganites: uncorrelated to correlated polarons, Physical Review B 73, 100408 (2006).

82. Beyer, G.: Isotopes in Medicine, Physics for Medical Imaging Applications, NATO SCIENCE SERIES, Volume 240, 2007, DOI: 10.1007/978-1-4020-5653-6, 267.

83. Köster, U., Hohn, A., Schibli, R., Türler, A., Zhernosekov, K., Miederer, M., Jensen, M., Barbet, J., Chatal, F., Haddad, F., Fagret, D., Polack, B., Vuillez, J.P., Ratib, O., Seimbille, Y., 
Tamburella, C., Pichler, B., Wiehr, S., and Assmann, W.: Innovative radio-isotopes for preclinical and clinical studies in nuclear medicine, CERN-INTC-2010-055 / INTC-I-12.

84. Hemmingsen, L., Sas, K.N., and Danielsen, E.: Biological applications of perturbed angular correlations of g-ray spectroscopy, Chem. Rev. 104, 4027 (2004).

85. Chain, C. Y., Ceolin, M., and Pasquevich, A. F.: PAC research in biology, Hyperfine Interactions 181, 619 (2008).

86. Butz, T., Saibene, S., Fraenzke, Th., and Weber, M., A TDPAC camera, Nucl. Instr. and Meth. A 284, 417 (1989).

87. Tröger, W., and the Isolde Collaboration : $\mathrm{Hg}$ (II) Coordination Studies in Penicillamine Enantiomers by ${ }^{199 \mathrm{~m}} \mathrm{Hg}$-TDPAC, Hyperfine Interactions 136/137, 673 (2001).

88. Gryboś, J., Marszałek, M., Lekka, M., Heinrich, F., and Tröger, W.: PAC Studies of BSA Conformational Changes, Hyperfine Interactions 159, 323 (2005).

89. Schilling, O., Vogel, A., Kostelecky, B., da Luz, H. N., Spemann, D., Späth, B., Marchfelder, A., Tröger, W., and Meyer-Klaucke, W.: Zinc- and iron-dependent cytosolic metallo-b-lactamase domain proteins exhibit similar zinc-binding affinities, independent of an atypical glutamate at the metal-binding site, Biochem. J. 385, 145 (2005).

90. Iranzo, O., Thulstrup, P. V., Ryu, S-B., Hemmingsen L., and Pecoraro, V. L.: The application of ${ }^{199} \mathrm{Hg}$ NMR and ${ }^{199 m} \mathrm{Hg}$ PAC Spectroscopies to Define the Biological Chemistry of $\mathrm{Hg}(\mathrm{II}): \mathrm{A}$ Case Study Using Designed Two and Three Stranded Coiled Coils. Chem. Eur. J. 13, 9178 (2007).

91. Heinz, U., Hemmingsen, L., Kiefer, M., and Adolph, H.W.: Structural Adaptability of Zinc Binding Sites: Different Structures in Partially, Fully, and Heavy-Metal Loaded States, Chem. Eur. J. 15, 7350 (2009).

92. Selevsek, N., Rival, S., Tholey, A., Heinzle, E., Heinz, U., Hemmingsen, L., and Adolph, H.W.: Zinc ion-induced domain organization in metallo- $\beta$-lactamases: A flexible "zinc arm" for rapid metal ion transfer?, J. Biol. Chem. 284, 16419 (2009).

93. Hastings, J. B., Siddons, D. P., van Bürck, U., Hollatz, R., and Bergmann, U.: Mössbauer spectroscopy using synchrotron radiation, Phys. Rev. Lett. 66, 770 (1991).

94. Seto, M., Masuda, R., Higashitaniguchi, S., Kitao, S., Kobayashi, Y., Inaba, C., Mitsui, T., and Yoda, Y.: Synchrotron-Radiation-Based Mössbauer Spectroscopy, Phys. Rev. Lett. 102, 217602 (2009).

95. Weyer, G.: Defects in semiconductors - results from Mössbauer spectroscopy, Hyperfine Interactions 177,1 (2007). 
96. Weyer, G.: Defect recovery of ion implanted InP, Nucl. Instr. and Meth. B 96, 315 (1995).

97. Fanciulli, M., Lindroos, M., Weyer, G., Moustakas, T.D., and the ISOLDE Collaboration : Sn Mössbauer Study of Ion Implanted GaN, Mat. Sci. Forum 196-201, 61 (1995).

98. Naidoo, D., Gunnlaugsson, H. P., Bharuth-Ram, K., Naicker, V. V., Weyer, G., Sielemann, R., Mantovan, R., Fanciulli, M., and the ISOLDE Collaboration : ${ }^{57} \mathrm{Fe}$ Mössbauer investigations in ptype silicon germanium single crystals, Hyperfine Interactions 188, 11 (2008).

99. Bharuth-Ram, K., Naicker, V.V., Naidoo, D., Gunnlaugsson, H.P., Mantovan, R., Weyer, G., Dietrich, M., Butler, J.E., and the ISOLDE Collaboration : Mössbauer study of ${ }^{57} \mathrm{Fe}$ in CVD diamond following ${ }^{57} \mathrm{Mn}$ implantation, Hyperfine Interactions 179, 17 (2008).

100. Weyer, G., Gunnlaugsson, H. P., Mantovan, R., Fanciulli, M., Naidoo, D., Bharuth-Ram, K., Agne, T.: Defect-related local magnetism at dilute Fe atoms in ion-implanted $\mathrm{ZnO}$, J. Appl. Phys. 102 (2007) 113915.

101. Gunnlaugsson, H.P., Weyer, G., Mantovan, R., Naidoo, D., Sielemann, R., Bharuth-Ram, K., Fanciulli, M, Johnston, K., Olafsson, S., and Langouche, G.: Isothermal defect annealing in semiconductors investigated by time-delayed Mössbauer spectroscopy: application to $\mathrm{ZnO}$, Hyperfine Interactions 188, 85 (2008).

102. Molholt, T.E., Mantovan, R., Gunnlaugsson, H.P., Bharuth-Ram, K., Fanciulli, M., Gislason, H.P., Johnston, K., Kobayashi, Y., Langouche, G., Masenda, H., Naidoo, D., Olafsson, S., Sielemann, R, and Weyer, G.: Temperature and dose dependence of defect complex formation with ion implanted $\mathrm{Mn} / \mathrm{Fe}$ in $\mathrm{ZnO}$, Physica B 404, 4820 (2009).

103. Gunnlaugsson, H.P., Mølholt, T.E., Mantovan, R., Masenda, H., Naidoo, D., Dlamini, W. B., Sielemann, R, Bharuth-Ram, K., Weyer, G., Johnston, K., Langouche, G., Ólafsson, S., Gíslason, H.P., Kobayashi, Y., Yoshida, Y., Fanciulli, M., and the ISOLDE Collaboration : Paramagnetism in $\mathrm{Mn} / \mathrm{Fe}$ implanted ZnO, Appl. Phys. Lett. 97, 142501 (2010) . 